\title{
Effects of various hydrogen peroxide bleaching concentrations and number of applications on enamel
}

\author{
Sandrine Bittencourt Berger', Luis Eduardo Silva Soares², Airton Abrahão Martin², \\ Gláucia Maria Bovi Ambrosano ${ }^{3}$, Cínthia Pereira Machado Tabchoury ${ }^{4}$, Marcelo Giannini ${ }^{5}$
}

'Universidade do Norte do Paraná - UNOPAR, School of Dentistry, Department of Restorative Dentistry, Londrina, PR, Brasil
2Universidade do Vale do Paraíba - Univap, Research and Development Institute (IP\&D), Laboratory of Biomedical Vibrational Spectroscopy,

São José dos Campos, SP, Brasil

3Universidade Estadual de Campinas - UNICAMP, Piracicaba Dental School, Department of Community Dentistry and Biostatistics, Piracicaba, SP, Brasil

${ }^{4}$ Universidade Estadual de Campinas - UNICAMP, Piracicaba Dental School, Department of Physiological Science, Piracicaba, SP, Brasil

${ }^{5}$ Universidade Estadual de Campinas - UNICAMP, Piracicaba Dental School, Department of Restorative Dentistry, Piracicaba, SP, Brasil

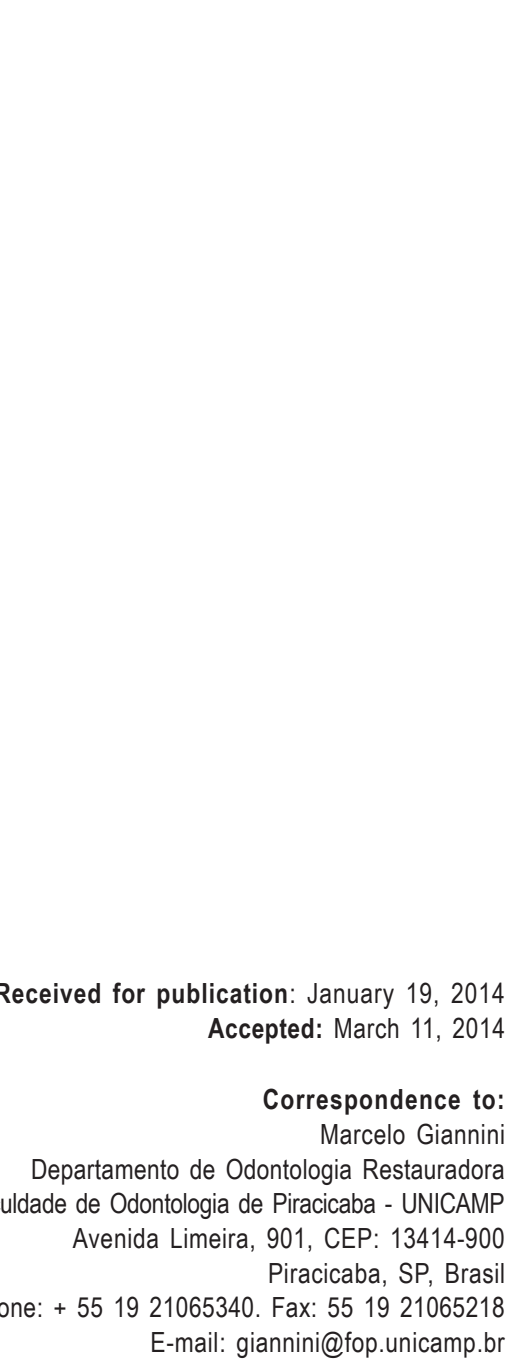

\begin{abstract}
Aim: To evaluate the effects of three hydrogen peroxide (HP) concentrations on enamel mineral content (MC), following three peroxide applications and using three methods to measure the MC. Methods: Forty samples were obtained from bovine incisors and randomly divided into 4 groups $(n=10)$. The control group remained untreated, while the experimental groups were tested for three HP concentrations (10\%, 35\% and 50\%). The HP gel was applied 3 times on the enamel surface for 30 min per application and the samples were analyzed after each application. The MC of the enamel was determined before and after bleaching using Fourier transform (FT-Raman) spectroscopy and micro energy-dispersive x-ray fluorescence spectrometry ( $\mu \mathrm{EDXRF})$. The calcium (Ca) lost from the bleached enamel was quantified with an atomic absorption spectrometer (AAS). The data were analyzed statistically by ANOVA, Tukey and Dunnett's tests $(p \leq 0.05)$. Results: The FT-Raman showed a decrease in MC for all bleaching treatments, without influence of the different HP concentrations or the number of applications. $\mu$ EDXRF did not detect any changes in MC. Conclusions: Ca loss was observed by the AAS, with no difference among the three HP concentrations. The FT-Raman and AAS analyses detected $\mathrm{MC}$ reduction and $\mathrm{Ca}$ loss after HP bleaching.
\end{abstract}

Keywords: dental enamel; bleaching agents; hydrogen peroxide.

\section{Introduction}

Tooth bleaching is a well-accepted method of treating stained and discolored teeth. The techniques comprise the application of a strong oxidizing agent as an active ingredient on a tooth surface to achieve a whitening effect ${ }^{1}$. The bleaching mechanism is based on the decomposition of peroxides into free radicals, which react with the organic pigment molecules, transforming them into smaller and less pigmented compounds ${ }^{2}$. Bleaching agents designed for professional use only contain a high concentration of peroxides (30\% to $40 \%$ ), while the active ingredient of patient-applied (at-home) tooth bleachers, present at lower concentrations, are carbamide peroxide (10\% to $20 \%$ ) and hydrogen peroxide (3\% to $7.5 \%)^{3}$.

Since the introduction of at-home bleaching in 1989 by Haywood and 
Heymann ${ }^{4}$, many studies have evaluated the effects of hydrogen and carbamide peroxides on mineralized and dental pulp tissues. A number of studies have reported some important side effects, such as increased roughness ${ }^{5}$, decreased microhardness ${ }^{5-7}$, reduction of enamel and dentin strength ${ }^{8}$, color changes ${ }^{9}$ and significant decrease in the calcium $(\mathrm{Ca})$, phosphate or carbonate concentration in enamel ${ }^{10-11}$. On the other hand, some authors have found no significant adverse effects following the bleaching ${ }^{12-13}$.

Such differences in the adverse effects on enamel and dentin caused by bleaching agents are due to the large number of bleaching protocols, peroxide types and concentrations, and evaluation methods. Regarding the methods, microhardness 2,5 , scanning electron and polarized light microscopy ${ }^{7,14}$, micro energy-dispersive $\mathrm{x}$-ray fluorescence spectrometry $(\mu \mathrm{EDXRF})^{11}$, Fourier transform-Raman (FTRaman) spectroscopy ${ }^{10}$ and atomic absorption spectrometer $(\mathrm{AAS})^{10}$ have been used to determine the adverse effects resulting from bleaching techniques.

The objective of this study was to analyze the effect of different hydrogen peroxide (HP) concentrations (10\%, 35\% and $50 \%$ ) after 1, 2 and 3 applications on an enamel surface, comparing three methodologies commonly used to evaluate the changes in the mineral contents of teeth. The research hypothesis was that HP promotes alterations in the mineral content of enamel regardless of the peroxide concentration and the number of peroxide applications.

\section{Material and methods}

\section{Tooth preparation and experimental groups}

Forty bovine incisors having the same age were used in this study. After extraction, the teeth were cleaned and stored in $0.1 \%$ thymol solution at $4{ }^{\circ} \mathrm{C}$ for 30 days. They were then submitted to manual debridement with a periodontal curette to remove organic debris. The root portion was removed with a diamond saw $2 \mathrm{~mm}$ below the dentin-enamel junction.

The enamel surface of all samples was flattened using 600-grit $\mathrm{Al}_{2} \mathrm{O}_{3}$ abrasive paper and polished with 1000- and 1200-grit aluminum oxide abrasive papers to remove irregularities from the bovine enamel surface ${ }^{6,10,15}$. The enamel surfaces of all teeth were coated with 2 layers of nail varnish (Revlon, New York, NY, USA), except for a standardized, central buccal area $\left(1 \mathrm{~cm}^{2}\right)$ for application of HP.

The teeth were randomly divided into 4 groups $(n=10)$, according to the HP concentration $(10 \%, 35 \%$ or $50 \%)$ and an unbleached control group. The teeth from the control group were kept in distilled water at $37{ }^{\circ} \mathrm{C}$.

\section{FT-Raman spectroscopy}

Spectra of the teeth before (baseline) and after enamel treatments (bleaching or control) were obtained using a FTRaman spectrometer (RFS 100/S; Bruker, Karlsruhe, Germany). All spectra were processed by adjusting five Raman vibrational stretching modes: $430 \mathrm{~cm}^{-1}$ (p1), $449 \mathrm{~cm}^{-1}$ (p2), $586 \mathrm{~cm}^{-1}$ (p3), $1043 \mathrm{~cm}^{-1}$ (p4) and $1073 \mathrm{~cm}^{-1}$ (p5). The p1-p3 represent phosphate modes and $\mathrm{p} 4$ and $\mathrm{p} 5$ are carbonate vibrations (type B carbonate) $)^{15-16}$. For the qualitative and semiquantitative spectral analysis, the spectra were corrected at baseline and then normalized to the $960 \mathrm{~cm}^{-1}$ peak ${ }^{17-18}$. The area of each band was obtained by Gaussian shapes. Microcal Origin Software (Microcal Software, Northampton, MA, USA) was used for calculating the integrated areas of the peaks for the unbleached and bleached samples ${ }^{19}$. The averages of integrated areas of the evaluated Raman peaks ( 1 to $\mathrm{p5}$ ) were calculated for the baseline and treated data.

\section{$\mu$ EDXRF spectrometry analysis}

The semi-quantitative elemental analyses of calcium $(\mathrm{Ca})$ (Ca wt.\%) and phosphorus (P) (P wt.\%) were conducted by an energy-dispersive micro $\mathrm{X}$-ray fluorescence spectrometer, model $\mu$ EDX 1300 (Shimadzu, Kyoto, Japan), equipped with a rhodium x-ray tube and a $\mathrm{Si}(\mathrm{Li})$ detector cooled by liquid nitrogen $\left(\mathrm{N}_{2}\right)$ and coupled to a computer system for data processing. The voltage in the tube was set at $15 \mathrm{kV}$, with an automatic adjustment of the current and a beam diameter of $50 \mu \mathrm{m}$. Three spectra from each specimen were collected before and after bleaching treatments. The measurements were performed with a count rate of $100 \mathrm{~s}$ per point (live time) and a dead time of $25 \%$. The energy range of the scans was 0.0 to $40.0 \mathrm{eV}$. The equipment was adjusted using a certified commercial reagent of stoichiometric hydroxyapatite [Aldrich, synthetic $\mathrm{Ca}_{10}\left(\mathrm{PO}_{4}\right)_{6}(\mathrm{OH})_{2}$, grade $99.999 \%$, lot $10818 \mathrm{HA}]$ as reference. The measurements were collected under fundamental parameters of characteristic x-ray emissions of $\mathrm{Ca}$ and $\mathrm{P}$, and the elements $\mathrm{O}$ and $\mathrm{H}$ were used as a chemical balance ${ }^{17,20}$. The energy calibration was performed using the internal standards of the equipment, as previously reported ${ }^{17,20}$.

\section{Bleaching procedures}

The bleaching agents were prepared using a rate of 10 parts of HP (Dinâmica Reagentes Analíticos, São Paulo, SP, Brazil) to 1 part of thickener (Carbopol Ultrez 10; Proderma, Piracicaba, SP, Brazil), and $\mathrm{pH}$ adjusted to 6.0 , according to a pilot study. A 2-mm thick layer of HP gel $(0.2 \mathrm{~g})$ was applied 3 times on the enamel surface for $30 \mathrm{~min}$ per application. Between applications, the samples were rinsed with $5 \mathrm{~mL}$ distilled and deionized water; this rinse was kept for AAS analysis.

\section{Atomic absorption spectrometer}

The rinse (HP and water) was evaluated using AAS. After each HP application, a standardized amount of water $(5 \mathrm{~mL})$ was used for rinsing and removing the peroxide gel from the enamel surface. The Ca concentration in the solution was measured using AAS (Varian Spectra AA50). Before the sample analysis, the equipment was calibrated with $\mathrm{Ca}$ standards ranging from 0.2 to $2.0 \mu \mathrm{g} / \mathrm{mL}$.

The concentrations of $\mathrm{Ca}$ in the peroxide gels were previously analyzed and were not found in significant amounts. Each analysis used lanthanum solution to reduce the interference of phosphate in the calcium analysis. 


\section{Data analysis}

The SAS software system (SAS Institute, Cary, NC, USA) was used for data analysis, with the significance set at 5\%. Data from the FT-RS analysis were analyzed by two-way ANOVA and Tukey's test. EDXRF data were analyzed by two-way ANOVA and Dunnett's test to compare the treated groups with the control group. AAS data were analyzed by two-way ANOVA, Tukey's test and Dunnett's test.

\section{Results}

The selected range of Raman spectra from the phosphate and carbonate main vibrational modes of enamel after 1,2 and 3 applications of HP are shown in Figures 1 to 3, respectively. The Raman spectra of the inorganic content did not show obvious reduction in intensity after treatments, compared with the non-treated and control group (Figures 1 - 3). The peaks at 430 and $449 \mathrm{~cm}^{-1}$ were associated to the ${ }_{12} \mathrm{PO}_{4}{ }^{3-}$ modes. The peak at $586 \mathrm{~cm}^{11}$ was attributed to phosphate ${ }_{14} \mathrm{PO}_{4}^{3-}$ vibrations and the peak $960 \mathrm{~cm}^{11}$ was related to ${ }_{11} \mathrm{PO}_{4}^{3-}$ vibration. The peaks at 1043 and $1073 \mathrm{~cm}^{\text {"1 }}$ were attributed to bending and stretching modes of carbonate $\left(\mathrm{CO}_{3}{ }^{2-} \text { ), respectively (Figures } 1-3\right)^{21}$.

Table 1 presents the means and standard deviations (SD) of the integrated area of the Raman peaks for the enamel before and after treatments. Two-way ANOVA revealed statistically significant differences for evaluation time $(\mathrm{p}=$ $0.0386)$. However, there was no significant difference between the HP gel concentrations $(\mathrm{p}=0.2144)$ or the number of applications $(\mathrm{p}=0.8982)$.

Table 2 exhibits the mean $\mathrm{Ca}, \mathrm{P}$ and $\mathrm{Ca} / \mathrm{P}$ ratio of enamel at baseline and after treatment, obtained by $\mu \mathrm{EDXRF}$

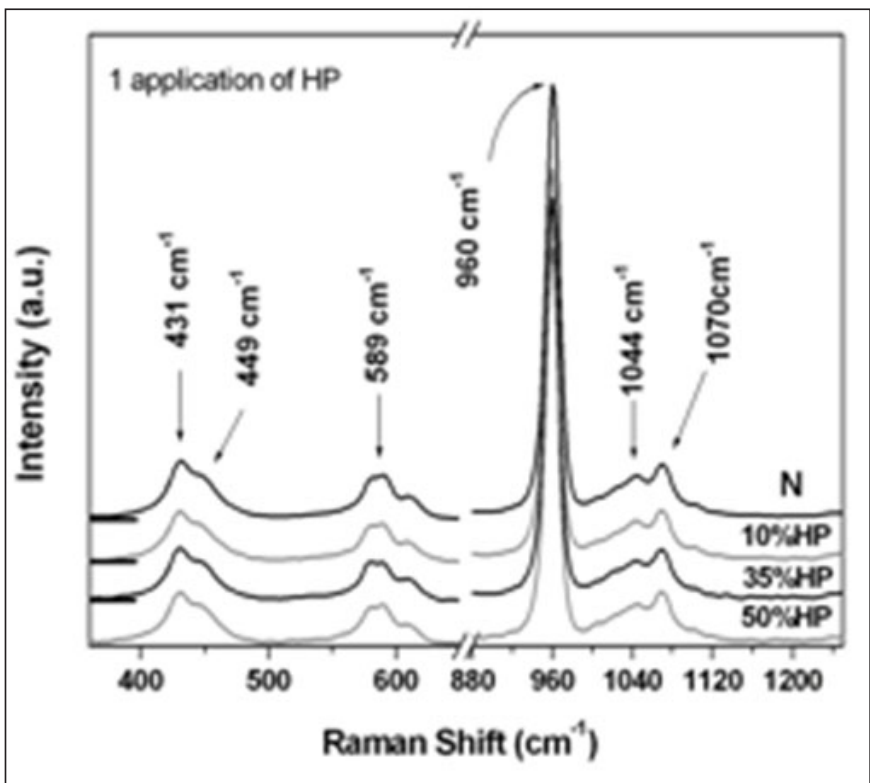

Fig. 1 - Raman spectra of untreated enamel (Normal, i.e., control group) and bleached enamel after 1 application of hydrogen peroxide (HP): 10\% HP, 35\% HP and 50\% HP. Raman spectra are shown in the 1250 to $650 \mathrm{~cm}^{-1}$ range, with inorganic peaks as follows: 431 and $449 \mathrm{~cm}-1$ ( $\mathrm{v}_{2} \mathrm{PO}_{4}{ }^{3-}$ vibrations), $589 \mathrm{~cm}^{-1}$ (phosphate $\mathrm{v}_{4} \mathrm{PO}_{4}^{3-}$ vibrations), $960 \mathrm{~cm}^{-1}$ (phosphate $\mathrm{V}_{1} \mathrm{PO}_{4}^{3-}$ vibrations), 1044 and $1070 \mathrm{~cm}^{-1}$ (bending and stretching modes of carbonate $-\mathrm{CO}_{3}{ }^{2-}$ ).

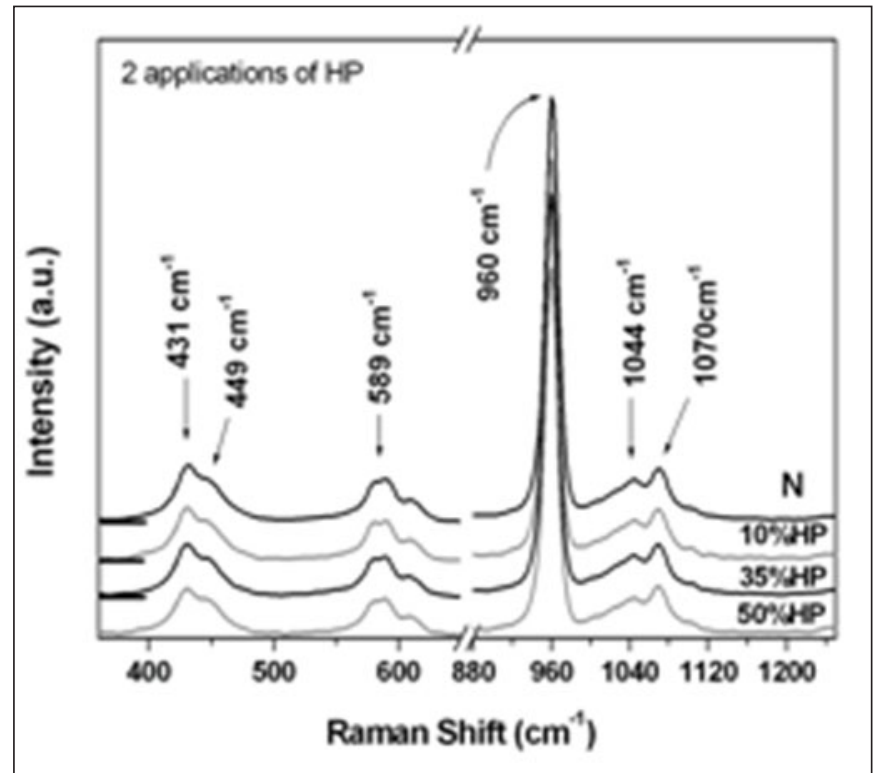

Fig. 2 - Raman spectra of untreated enamel (Normal, i.e., control group) and bleached enamel after 2 applications of hydrogen peroxide (HP): 10\% HP, 35\% HP and $50 \%$ HP. Raman spectra are shown in the 350 to $1250 \mathrm{~cm}^{-1}$ range, with inorganic peaks as follows: 431 and $449 \mathrm{~cm}^{-1}$ ( $\mathrm{v}_{2} \mathrm{PO}_{4}{ }^{3-}$ vibrations), $589 \mathrm{~cm}^{-1}$ (phosphate $\mathrm{V}_{4} \mathrm{PO}_{4}^{3-}$ vibrations), $960 \mathrm{~cm}^{-1}$ (phosphate $\mathrm{V}_{1} \mathrm{PO}_{4}^{4-}$ vibrations), 1044 and $1070 \mathrm{~cm}^{-1}$ (bending and stretching modes of carbonate $-\mathrm{CO}_{3}^{2-}$ ).

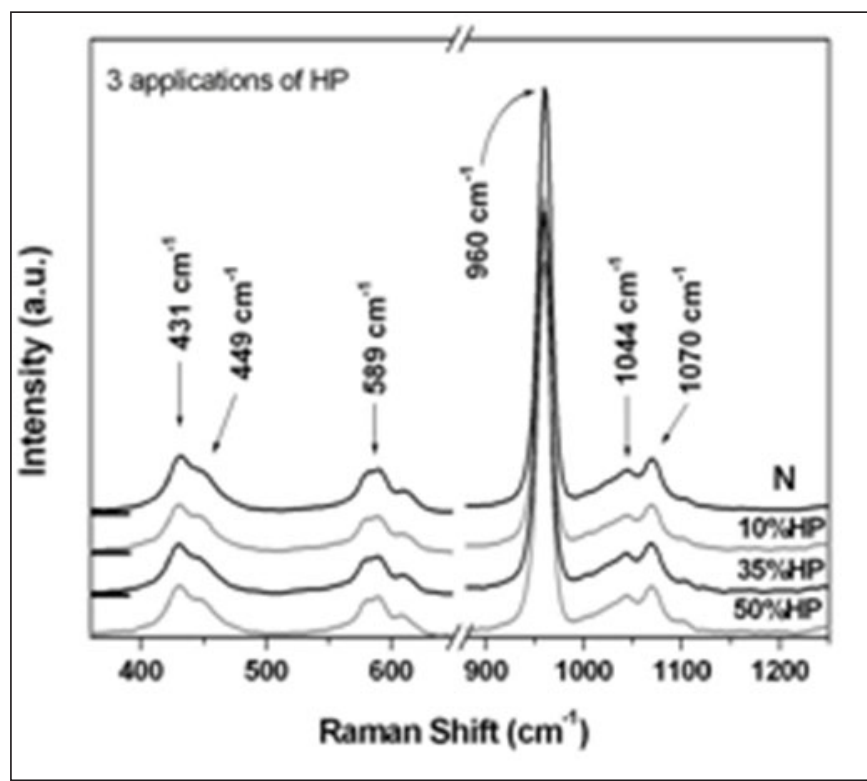

Fig. 3 - Raman spectra of untreated enamel (Normal, i.e., control group) and bleached enamel after 3 applications of hydrogen peroxide (HP): 10\% HP, 35\% HP and 50\% HP. Raman spectra are shown in the 350 to $1250 \mathrm{~cm}^{11}$ range, with inorganic peaks as follows: 431 and $449 \mathrm{~cm}^{-1}$ ( $\mathrm{i}_{2} \mathrm{PO}_{4}{ }^{3-}$ vibrations), $589 \mathrm{~cm}^{-1}$ (phosphate $\mathrm{V}_{4} \mathrm{PO}_{4}^{3-}$ vibrations), $960 \mathrm{~cm}^{-1}$ (phosphate $\mathrm{V}_{1} \mathrm{PO}_{4}^{3-}$ vibrations), 1044 and $1070 \mathrm{~cm}^{-1}$ (bending and stretching modes of carbonate $-\mathrm{CO}_{3}{ }^{2}$ ).

analysis. There was no statistically significant difference among the peroxide concentrations $(p=0.1344)$, number of applications $(p=0.1951)$, evaluation times $(p=0.4420)$ or the control group compared with the bleached experimental groups $(\mathrm{p}=0.6259)$.

The results of AAS are depicted in Table 3. All experimental bleached groups differed from the unbleached control group, according to Dunnett's test $(\mathrm{p}<0.05)$. The 
Table 1 - Mean (standard deviation) of the integrated area of Raman peaks (p1 to p5) at baseline and after bleaching.

\begin{tabular}{lcl}
\hline Groups & Before bleaching (baseline) & After bleaching \\
Control Group & $67.8(4.1) \mathrm{A} \mathrm{a}$ & $65.4(3.6) \mathrm{A} \mathrm{a}$ \\
$10 \% \mathrm{HP}+1$ application & $68.0(7.5) \mathrm{A} \mathrm{a}$ & $56.0(5.8) \mathrm{B} \mathrm{a}$ \\
$10 \% \mathrm{HP}+2$ applications & $67.0(8.2) \mathrm{A} \mathrm{a}$ & $56.4(5.7) \mathrm{B} \mathrm{a}$ \\
$10 \% \mathrm{HP}+3$ applications & $63.8(2.4) \mathrm{A} \mathrm{a}$ & $58.7(2.4) \mathrm{B} \mathrm{a}$ \\
$35 \% \mathrm{HP}+1$ application & $70.3(8.4) \mathrm{A} \mathrm{a}$ & $61.5(5.6) \mathrm{B} \mathrm{a}$ \\
$35 \% \mathrm{HP}+2$ applications & $67.9(8.6) \mathrm{A} \mathrm{a}$ & $58.4(8.8) \mathrm{B} \mathrm{a}$ \\
$35 \% \mathrm{HP}+3$ applications & $71.2(4.1) \mathrm{A} \mathrm{a}$ & $60.5(8.3) \mathrm{B} \mathrm{a}$ \\
$50 \% \mathrm{HP}+1$ application & $69.4(9.8) \mathrm{A} \mathrm{a}$ & $56.7(3.6) \mathrm{B} \mathrm{a}$ \\
$50 \% \mathrm{HP}+2$ applications & $69.3(4.1) \mathrm{A} \mathrm{a}$ & $59.8(7.5) \mathrm{B} \mathrm{a}$ \\
$50 \% \mathrm{HP}+3$ applications & $69.2(6.6) \mathrm{A} \mathrm{a}$ & $60.6(4.8) \mathrm{B} \mathrm{a}$ \\
\hline
\end{tabular}

Means followed by different letters, capital letters in rows and lowercase letters in columns, are statistically different by Tukey' test $(p \leq 0.05)$. HP: hydrogen peroxide

Table 2 - Means of element content in wt\% (standard deviation) in enamel surface.

\begin{tabular}{|c|c|c|c|c|c|c|}
\hline \multirow[t]{3}{*}{ Groups } & \multicolumn{6}{|c|}{ Element Content (wt\%) } \\
\hline & \multicolumn{2}{|c|}{$\mathrm{Ca}($ mean $\pm \mathrm{SD})$} & \multicolumn{2}{|c|}{$\mathrm{P}($ mean $\pm \mathrm{SD})$} & \multicolumn{2}{|c|}{$\mathrm{Ca} / \mathrm{P}($ mean $\pm \mathrm{SD})$} \\
\hline & $\begin{array}{c}\text { Before } \\
\text { treatments }\end{array}$ & $\begin{array}{c}\text { After } \\
\text { treatments }\end{array}$ & $\begin{array}{c}\text { Before } \\
\text { treatments }\end{array}$ & $\begin{array}{c}\text { After } \\
\text { treatments }\end{array}$ & $\begin{array}{l}\text { Before } \\
\text { treatments }\end{array}$ & $\begin{array}{c}\text { After } \\
\text { treatments }\end{array}$ \\
\hline Control Group & $30.7(7.8)$ & $32.3(7.7)$ & $15.6(3.9)$ & $16.1(4.4)$ & $2.0(0.1)$ & $2.0(0.1)$ \\
\hline 10\% HP + 1 application & $34.0(5.8)$ & $32.8(3.9)$ & $17.3(2.5)$ & $16.8(2.3)$ & $2.0(0.1)$ & $2.0(0.1)$ \\
\hline $10 \%$ HP + 2 applications & $30.1(3.9)$ & $28.9(6.1)$ & $16.5(2.8)$ & $15.0(3.7)$ & $1.8(0.1)$ & $1.9(0.2)$ \\
\hline $10 \%$ HP +3 applications & $33.9(2.4)$ & $31.7(2.6)$ & $17.7(1.2)$ & $16.1(1.6)$ & $1.9(0.1)$ & $2.0(0.1)$ \\
\hline $35 \%$ HP + 1 application & $34.0(7.8)$ & $30.4(2.8)$ & $17.5(5.9)$ & $15.1(1.7)$ & $2.0(0.3)$ & $1.9(0.1)$ \\
\hline $35 \%$ HP + 2 applications & $37.2(3.7)$ & $31.6(7.1)$ & $19.1(1.9)$ & $16.4(3.7)$ & $1.9(0.1)$ & $1.9(0.1)$ \\
\hline $35 \%$ HP + 3 applications & $34.7(5.1)$ & $33.2(4.4)$ & $17.9(1.7)$ & $16.9(2.0)$ & $1.9(0.1)$ & $2.0(0.1)$ \\
\hline $50 \%$ HP + 1 application & $32.7(1.0)$ & $35.3(1.9)$ & $17.4(0.7)$ & $18.2(0.7)$ & $1.9(0.1)$ & $1.9(0.1)$ \\
\hline $50 \%$ HP + 2 applications & $35.6(4.0)$ & $33.9(3.2)$ & $19.1(1.9)$ & $19.4(2.2)$ & $1.9(0.1)$ & $1.9(0.1)$ \\
\hline $50 \%$ HP + 3 applications & $30.4(3.9)$ & $33.0(2.2)$ & $17.5(6.3)$ & $16.7(1.5)$ & $1.8(0.3)$ & $2.0(0.1)$ \\
\hline
\end{tabular}

There was no statistically significant difference among the experimental groups. HP: hydrogen peroxide

Table 3 - Concentration of calcium $(\mu \mathrm{g} / \mathrm{mL})$ in hydrogen peroxide (HP) gels and rinsing water from the bleached enamel surfaces.

\begin{tabular}{llll}
\hline HP Concentration & \multicolumn{3}{c}{ Number of Applications } \\
& 1 Application & 2 Applications & 3 Applications \\
\hline $10 \%$ & $142.6(27.5) \mathrm{Aa}^{*}$ & $128.7(44.8) \mathrm{Aa}^{*}$ & $42.3(15.9) \mathrm{Ba}^{*}$ \\
$35 \%$ & $131.8(17.7) \mathrm{Aa}^{*}$ & $149.5(25.4) \mathrm{Aa}^{*}$ & $29.8(6.3) \mathrm{Ba}^{*}$ \\
$50 \%$ & $120.1(28.0) \mathrm{Aa}^{*}$ & $102.5(20.8) \mathrm{Aa}^{*}$ & $33.6(8.4) \mathrm{Ba}^{*}$ \\
Control Group & $2.8(1.6)$ & & \\
\hline
\end{tabular}

Means followed by different letters, capital letters in rows and lowercase letters, in columns are statistically different by Tukey's test $(p \leq 0.05)$. Means followed by asterisk $\left(^{*}\right)$ differ from control group by Dunnett's test $(p \leq 0.05)$.

HP concentration had no influence on $\mathrm{Ca}$ loss in any of the applications ( $p=0.0884)$. The first and second applications of HP released significantly higher values of $\mathrm{Ca}$ in the rinse compared with the third $(\mathrm{p}<0.0001)$.

\section{Discussion}

$\mu$ EDXRF, FT-Raman and AAS are versatile and nondestructive techniques that allow use of the same samples for the various types of dental enamel analysis. These methods provide precise concentrations of $\mathrm{Ca}$, phosphate and carbonate and the $\mathrm{Ca} / \mathrm{P}$ ratio, as shown in the Results section. The hypothesis that HP promotes alterations in the mineral content of enamel regardless of peroxide concentration or number of peroxide applications was accepted only after using the FT-Raman and AAS methods.

FT-Raman analysis showed that HP decreased the integrated area of Raman peaks of enamel samples (Table 1 and Figures 1 - 3). On the other hand, the control group, in which the specimens were not bleached, no enamel chemical changes were observed, as expected. Alterations in mineral content of enamel promoted by peroxides have also been detected by other studies using FT-Raman ${ }^{10,15,22}$. In this study, 
the number of applications did not decrease the integrated area of Raman peaks, indicating that, up to $3 \mathrm{HP}$ applications, the effects of peroxides were similar. However, Bistey et al. ${ }^{22}$ reported that changes in the enamel surface were directly proportional to the HP concentration. In addition, these changes in the area of the peaks were more obvious when the duration of bleaching was 30 and $60 \mathrm{~min}$. The $30-\mathrm{min}$ time used in this study may not have been able to promote more alterations in enamel surface after first, second or third applications of bleaching agent regardless of the HP concentration. A previous ${ }^{10}$ has shown similar results on human enamel after using 35\% HP, testing three commercially available, bleaching agents applied for $30 \mathrm{~min}$.

The $\mu$ EDXRF analysis provides information about tooth mineral content and could be used as an analytical technique to study chemical changes on enamel ${ }^{20}$. However, in the conducted study it was not possible to identify any changes in mineral phase using this method, even after three 50\% HP applications. Smidt et al. ${ }^{13}$ also found no significant changes in the enamel $\mathrm{Ca} / \mathrm{P}$ ratio after bleaching. Conversely, some authors reported a reduction in the $\mathrm{Ca} / \mathrm{P}$ ratio ${ }^{12,23}$. Rotstein et al. ${ }^{12}$ found a significant reduction in the $\mathrm{Ca} / \mathrm{P}$ ratio following treatment with $35 \%$ HP for 7 days. Also, Oltu and Gurgan ${ }^{24}$ observed a significant decrease in the $\mathrm{Ca} / \mathrm{P}$ ratio after bleaching with $35 \%$ carbamide peroxide compared with low carbamide peroxide concentrations. In that study, the bleaching agents were applied for $8 \mathrm{~h} /$ day for 6 weeks. Poorni et al. $^{25}$ found decrease of $\mathrm{Ca} / \mathrm{P}$ ratio in human enamel after 30 -min exposure to $35 \% \mathrm{HP}$. Some reasons to the for variations of results among studies are due to different bleaching protocols, peroxide concentrations, type of bleaching agent and morphological differences between human and bovine enamel. The current study used flat and polished bovine enamel in order to remove the irregularities present in the buccal surface, which could interfere in the $\mu$ EDXRF and FT-Raman analysis ${ }^{5,10,16}$.

Previous studies have detected that peroxide bleaching induces $\mathrm{Ca}$ loss from dental enamel ${ }^{10,26}$. These investigations used AAS in an attempt to quantify the concentration of $\mathrm{Ca}$ lost after bleaching. This study compared three HP concentrations and found that, with the same number of applications, there were no significant differences among the HP bleaching agents regardless of using high and low concentrations. Conversely, Tezel et al. ${ }^{27}$ found more $\mathrm{Ca}$ ions lost from the enamel surface after 35\% and 38\% HP bleaching than with $10 \%$ carbamide peroxide treatment. The authors suggested that the significant enamel $\mathrm{Ca}$ loss was due to the high potential of concentrated HP to cause dental demineralization. The low stability of highly concentrated peroxides and the fast peroxide degradation reaction may lead to less interaction of the peroxide with the enamel structure ${ }^{28}$, causing the same alteration when using low or high concentrations, as observed in this study. Al-Salelhi et al. ${ }^{6}$ investigated the effect of $24 \mathrm{~h}$ non-stop $3 \%, 10 \%$ or $30 \%$ HP concentration on mineral loss and found increased ion release with increasing HP concentration. It may be speculated that the higher values of $\mathrm{Ca}$ loss may be due to the longer exposure time ( $24 \mathrm{~h}$ versus 30 min used in the present work).

The $\mathrm{Ca}$ bonded weakly to the hydroxyapatite and it was lost mostly after the first and second peroxide applications, according to the AAS method. Thus, after the third application of peroxide, the $\mathrm{Ca}$ concentration decreased significantly in the rinsing solution (HP and water). According to Wang et al. ${ }^{29}$ the release of $\mathrm{Ca}$ from the enamel apatite may occur via atomic diffusion through the apatite channels along the crystallographic c-axis and the inter-crystallites and inter-rod special voids with openings on the surface. Another reason for bleaching having enhanced $\mathrm{Ca}$ leaching could be the degradation of the enamel organic component, which removes related mineral elements. Calcium removed by the HP application is the one present in the hydroxyapatite crystal, the building block of dental hard tissues. Probably polishing of the enamel surface, made in the present study in order to remove irregularities from the bovine enamel surface, produced a more reactive surface and in the first and second applications of HP, independent of its concentration, a greater amount of $\mathrm{Ca}$ was removed from the crystal. Another hypothesis that could help explaining the present findings is that the mineral content of enamel changes from the surface to inside and $\mathrm{Ca}$ concentrations were shown to decrease from the surface to the inside of the enamel ${ }^{30}$. However, further studies are required to elucidate this mineral loss due to HP application.

Bovine teeth were used in this study because their chemical properties and the prismatic morphology are very similar to human enamel as reported by Yassen et al. ${ }^{31}$ and Reis et al. ${ }^{32}$, respectively. Studied have used bovine teeth as substitute for human teeth also in cosmetic dentistry and dental bleaching ${ }^{6,21}$. However, the comparison of these findings with studies using human teeth must be careful because of the variations in bovine tooth age and the different methodologies used to prepare the samples.

This study did not test commercial whitening products; the used bleaching gels were a mixture of HP and a thickener. The commercially available bleaching agents have in their composition some additives like fluoride ions, potassium nitrate, carpobol, propylene glycol, sodium fluoride, calcium and others. These additives may minimize the mineral loss and produce different results from those obtained in this study. More studies are required to investigate the role of each component in the enamel mineral loss. An important factor that must be considered is that in this study the amount of bleaching agent used was standardized $(2 \mathrm{~mm}$ thick on the enamel surface), since many studies do not mention the amount of bleaching agent used. There are no studies in the literature correlating the amount of bleaching agent and its effects on tooth structure.

Different methods were used in the present study to assess the mineral content of enamel after the bleaching treatment. While $\mu$ EDXRF did not identify any changes in mineral content after bleaching, FT-Raman and AAS detected alterations in mineral components and $\mathrm{Ca}$ loss, respectively. The analysis of mineral content of enamel after bleaching 
requires the knowledge of the accuracy and limitations of each method used. The effect of dental bleaching on enamel mineral content has been frequently evaluated using EDXRF, FT-Raman and AAS, and the findings of the present study showed that these methods are accurate for this purpose. When used separately, different results were found for each method and this should be considered when comparing studies with different methodologies.

According to the FT-Raman and AAS methods of detection, HP bleaching causes a reduction in the mineral content of enamel. Increasing the HP concentration did not increase the mineral loss.

\section{Acknowledgments}

This study was supported by grants \#01/14384-8, \#05/ 50811-9, \#07/54784-1 and \#05/60696-2 from the São Paulo State Research Foundation (FAPESP).

\section{References}

1. Dahl JE, Pallesen U. Tooth bleaching - a critical review of the biological aspects. Crit Rev Oral Biol Med. 2003; 14: 292-304.

2. Unlu N, Cobankara FK, Altinoz C, Ozer F. Effect of home bleaching agents on the microhardness of human enamel and dentin. J Oral Rehabil. 2004; $31: 57-61$.

3. Joiner A. The bleaching of teeth: a review of the literature. J Dent. 2006; 34: 412-9.

4. Haywood VB, Heymann HO. Nightguard vital bleaching. Quintessence Int. 1989; 20: 173-6.

5. Pinto CF, Oliveira R, Cavalli V, Giannini M. Peroxide bleaching agent effects on enamel surface microhardness, roughness and morphology. Braz Oral Res. 2004; 18: 306-11.

6. Al-Salehi SK, Wood DJ, Hatton PV. The effect of $24 \mathrm{~h}$ non-stop hydrogen peroxide concentration on bovine enamel and dentine mineral content and microhardness. J Dent. 2007; 35: 845-50.

7. Berger SB, Cavalli V, Ambrosano GM, Giannini M. Changes in surface morphology and mineralization level of human enamel following in-office bleaching with $35 \%$ hydrogen peroxide and light irradiation. Gen Dent. 2010; 58: e74-9.

8. Cavalli V, de Carvalho RM, Giannini M. Influence of carbamide peroxidebased bleaching agents on the bond strength of resin-enamel/dentin interfaces. Braz Oral Res. 2005; 19: 23-9.

9. Matis BA, Cochran MA, Eckert G. Review of the effectiveness of various tooth whitening systems. Oper Dent. 2009; 34: 230-5.

10. Berger SB, Cavalli V, Martin AA, Soares LE, Arruda MA, Brancalion $\mathrm{ML}$, et al. Effects of combined use of light irradiation and $35 \%$ hydrogen peroxide for dental bleaching on human enamel mineral content. Photomed Laser Surg. 2010; 28: 533-8.

11. Cimilli $\mathrm{H}$, Pameijer $\mathrm{CH}$. Effect of carbamide peroxide bleaching agents on the physical properties and chemical composition of enamel. Am J Dent. 2001; 14: 63-6.

12. Rotstein I, Dankner E, Goldman A, Heling I, Stabholz A, Zalkind M. Histochemical analysis of dental hard tissues following bleaching. J Endod. 1996; 22: 23-5.

13. SmidtA, Feuerstein O, Topel M. Mechanical, morphologic, and chemical effects of carbamide peroxide bleaching agents on human enamel in situ. Quintessence Int. 2011; 42: 407-12.

14. McGuckin RS, Babin JF, Meyer BJ. Alterations in human enamel surface morphology following vital bleaching. J Prosthet Dent. 1992; 68: 754-60.
15. Cavalli V, Rodrigues LK, Paes-Leme AF, Soares LE, Martin AA, Berger $\mathrm{SB}$, etal. Effects of the addition of fluoride and calcium to low-concentrated carbamide peroxide agents on the enamel surface and subsurface. Photomed Laser Surg. 2011; 29: 319-25.

16. da Silva Tagliaferro EP, Rodrigues LK, Soares LE, Martin AA, Nobredos-Santos M. Physical and compositional changes on demineralized primary enamel induced by CO2 Laser. Photomed Laser Surg. 2009; 27: 585-90.

17. Pascon FM, Kantovitz KR, Soares LE, Santo AM, Martin AA, PuppinRontani RM. Morphological and chemical changes in dentin after using endodontic agents: Fourier transform Raman spectroscopy, energydispersive x-ray fluorescence spectrometry, and scanning electron microscopy study. J Biomed Opt. 2012; 17: 075008.

18. Penel G, Leroy G, Rey C, Bres E. MicroRaman spectral study of the $\mathrm{PO} 4$ and $\mathrm{CO} 3$ vibrational modes in synthetic and biological apatites. Calcif Tissue Int. 1998; 63: 475-81.

19. Soares LE, Cesar IC, Santos CG, De Cardoso AL, Liporoni PC, Munin, et al. Influence of coffee on reflectance and chemistry of resin composite protected by surface sealant. Am J Dent. 2007; 20: 299-304.

20. Soares LE, do Espirito Santo AM, Brugnera A, Zanin FA, Martin AA. Effects of Er: YAG laser irradiation and manipulation treatments on dentin components, part 2: energy-dispersive $\mathrm{X}$-ray fluorescence spectrometry study. J Biomed Opt. 2009; 14: 024002.

21. Park HJ, Kwon TY, Nam SH, Kim HJ, Kim KH, Kim YJ. Changes in bovine enamel after treatment with a $30 \%$ hydrogen peroxide bleaching agent. Dent Mater J. 2004; 23: 517-21.

22. Bistey T, Nagy IP, Simo A, Hegedus C. In vitro FT-IR study of the effects of hydrogen peroxide on superficial tooth enamel. J Dent. 2007; 35: 32530.

23. Paula SS, Soares LE, do Espirito Santo AM, Martin AA, Cavalli V, Liporoni PC. FT-Raman and energy dispersive X-ray fluorescence spectrometric analyses of enamel submitted to $38 \%$ hydrogen peroxide bleaching, an acidic beverage, and simulated brushing. Photomed Laser Surg. 2010; 28: 391-6.

24. Oltu U, Gurgan S. Effects of three concentrations of carbamide peroxide on the structure of enamel. J Oral Rehabil. 2000; 27: 332-40.

25. Poorni S, Kumar RA, Shankar P, Indira R, Ramachandran S. Effect of $10 \%$ sodium ascorbate on the calcium: phosphorus ratio of enamel bleached with $35 \%$ hydrogen peroxide: an in vitro quantitative energydispersive X-ray analysis. Contemp Clin Dent. 2010; 1: 223-6.

26. Cavalli V, Rodrigues LK, Paes-Leme AF, Brancalion ML, Arruda MA, Berger SB, et al. Effects of bleaching agents containing fluoride and calcium on human enamel. Quintessence Int 2010; 41: e157-165.

27. Tezel H, Ertas OS, Ozata F, Dalgar H, Korkut ZO. Effect of bleaching agents on calcium loss from the enamel surface. Quintessence Int. 2007; 38: 339-47.

28. Broughton DB, Wentworth RL, Laing ME. Mechanism of decomposition of hydrogen peroxide solutions with manganese dioxide. J Am Chem Soc. 1947; 69: 744-7.

29. Wang X, Mihailova B, Klocke A, Fittschen UE, Heidrich S, Hill M et al. Side effects of a non-peroxide-based home bleaching agent on dental enamel. J Biomed Mater Res A. 2009; 88: 195-204.

30. Weatherell JA, Robinson C, Hallsworth AS. Variations in the chemical composition of human enamel. J Dent Res. 1974; 53: 180-92.

31. Yassen GH, Platt JA, Hara AT. Bovine teeth as substitute for human teeth in dental research: a review of literature. J Oral Sci. 2011; 53: 273-82.

32. Reis AF, Giannini M, Kavaguchi A, Soares CJ, Line SR. Comparison of microtensile bond strength to enamel and dentin of human, bovine, and porcine teeth. J Adhes Dent. 2004; 6: 117-21. 